\title{
Designing Collaborative Learning Experiences for Library
}

\section{Computer Classrooms}

\section{Stefan A. Smith}

\begin{abstract}
Collaborative learning, a form of active learning, can be used in computer classrooms to provide effective library instruction. Librarians have used collaborative learning in traditional classrooms and are beginning to incorporate it into hands-on computer classrooms. As librarians develop computer-based collaborative environments, they will likely face issues that lead them to reconsider how they approach facility design, curricular strategies, student expectations, teaching styles, and classroom time management. This article makes a case for using collaborative learning within library computer classrooms and describes how librarians at a medium-sized university made the transition from hands-on individualized learning to hands-on collaborative learning.
\end{abstract}

KEYWORDS. Collaborative learning, group learning, active learning, library instruction, information literacy, teaching techniques, classroom management, classroom furniture, computer classroom design

Stefan A. Smith (MLIS, University of Wisconsin-Milwaukee; MA, George Washington University) is Outreach Librarian, Murphy Library, University of Wisconsin-La Crosse, La Crosse, WI 54601 (address e-mail to: smith.stef@uwlax.edu). 


\section{Designing Collaborative Learning Experiences for Library Computer}

\section{Classrooms}

\section{INTRODUCTION}

A look inside a typical academic library computer classroom reveals twenty to thirty students sitting quietly, each bent into a monitor, each individually involved with the computer before them. The lights are dim, and a librarian is somewhere near the front of the room pointing to a screen and talking. Students are involved in a variety of activities: some are on-task and following the instructor, some are trying to catch up, some have completed the current task and are waiting, and some are engaged in unrelated computing activities. This is the computer classroom setting that most librarians and students experience and for which most curricula and facilities are designed. It reflects and supports long-standing, traditional educational theories and practices.

A glance inside a collaborative computer classroom reveals a different experience. Several groups of students are clustered around computers, three to five students per group. The room is alive with discussion and debate. The lights are bright, and the librarian is busy moving among groups, strategizing and brainstorming. Students are active, their hands, heads, and faces in motion. Within each group, all members are on the same task. Students feel comfortable talking and asking questions of each other and the instructor. This classroom reflects more current educational theories, which direct students to construct their own paths to knowledge through socially-relevant, peer-based learning experiences.

In collaborative learning, small groups of learners work together toward common objectives, practicing open and dynamic methods of inquiry while building knowledge grounded 
in socially-relevant contexts. While distinctions can be made among collaborative, cooperative, and group learning, in this article, they are seen as roughly synonymous. They collectively represent methods of active learning in which small groups of students share the accountability for discovery and learning. Collaborative learning is a logical derivative of constructivist learning theory, the foremost philosophy of current educational studies and practices. Constructivist learning theory asserts that knowledge is self-created and built on the structural underpinnings of previously acquired understandings (Howe and Berv 2000). Cognition takes hold when ideas are processed and made relevant within the cultural context of the learner (McLoughlin and Oliver 1998). Constructivist learning theory forms the philosophical backdrop for many current methods, strategies, and techniques of learning, including active, experiential, collaborative, problem based, and case based learning, to name a few.

In the early 1900's, John Dewey introduced active learning, a concept now familiar to most librarians. At the same time, he discussed collaborative learning, suggesting that group negotiations and ideas generated by discussion and explanation were instrumental in discovery and learning (Hung 2002). Since then, collaborative learning has been frequently studied and its effectiveness verified (Will 1997). In the field of librarianship, studies have found that undergraduates preferred collaborative learning over individual learning (Dabbour 1997) and that when traditional bibliographic lectures were redesigned to include small-group, hands-on components, they were seen as more positive and effective (Drueke 1992). Collaborative learning has also been frequently studied in hands-on computer classrooms. In a meta-analysis of 122 studies involving 11,317 learners, Yiping, Abrami, and d'Apollonia concluded that "when working with computer technology in small groups, students in general produced substantially 
better group products than individual products and they also gained more individual knowledge than those learning with computer technology individually $(2001,476) . ”$

Many instruction programs still use a form of teaching in which the librarian demonstrates an activity and students try to replicate it (Hollister and Coe 2003). This is especially common in computer classrooms, most of which have been designed specifically to support this mimetic style of learning. Hollister and Coe (2003) assert that while most librarians favor active learning methods in theory, in practice they may avoid it because it seems to take more time. Collaborative learning is further deterred because most hands-on facilities have been designed to support individualized learning activities at the expense of group interaction. Given these hindering factors, it is little wonder that collaborative learning has not been more deeply integrated into library computer classrooms.

Librarians and students at the University of Wisconsin-La Crosse have had positive experiences using collaborative methods in hands-on classes that had previously used more traditional methods of instruction. The University of Wisconsin at La Crosse is home to approximately 8,000 students, mostly undergraduates. Murphy Library, the university’s single, centralized library, has an active information literacy instruction program reaching approximately 5,000 participants each year. The director of this program encourages librarians to experiment with diverse teaching styles and techniques, and the program has a history of using a variety of active learning methods. In 2002, the author of this article began using collaborative learning methods in hands-on classes in computer classrooms. The first sessions were with returning adult learners who had a wide variety of information literacy skills and who had unique individual needs. Collaborative learning was seen as a way to blend the inconsistencies in skill levels. Through natural group interaction, the skills and experience of advanced students were 
expected to move individual groups, and eventually entire classes, forward. This initial implementation of collaborative learning within the computer classroom was judged a success by instructors and learners alike, leading to the use of hands-on collaborative learning in a variety of other classes ranging from freshman-level English to graduate-level Business.

\section{THE PHYSICAL ENVIRONMENT}

Collaborative work is most effective in environments that have been purposefully designed to meet the unique needs of group learners and teachers. The design and layout of computer classrooms may greatly affect pedagogical approaches and how they are implemented within the rooms (Huang and Lee 2001). A well planned design uses furniture built for group work, technology that facilitates collaboration, and space that allows for flexibility in pedagogical approach. At Murphy Library, the existing hands-on instruction room was modified to be effective with both individual and group instruction, similar to Figure 1.

Room layout should allow learners to form ad-hoc groups with ease while encouraging interaction within and among groups, and between teachers and groups. Clear lines of sight should exist between group members, instructors, and projection screens. In some cases, this may mean having all group tables face the same direction. In others, it may mean having redundant projection screens on more than one wall. Although the choices and decisions that accompany room layout are not overly complex, significant changes may be necessary when adapting a room previously built for individualized learning. For example, at Murphy Library, a substantial effort that included carpet removal and trenching went into bringing power outlets to the center of a room where outlets had previously existed only along outside walls. Room 
designers will want to take into account issues of accessibility as well, ensuring that access lanes are free of cables or other obstructions. Huang and Lee (2001) in their Chinese-language article, and Lowery (1998) itemize a number of logical and physical arrangements that allow learners and teachers to interact flexibly.

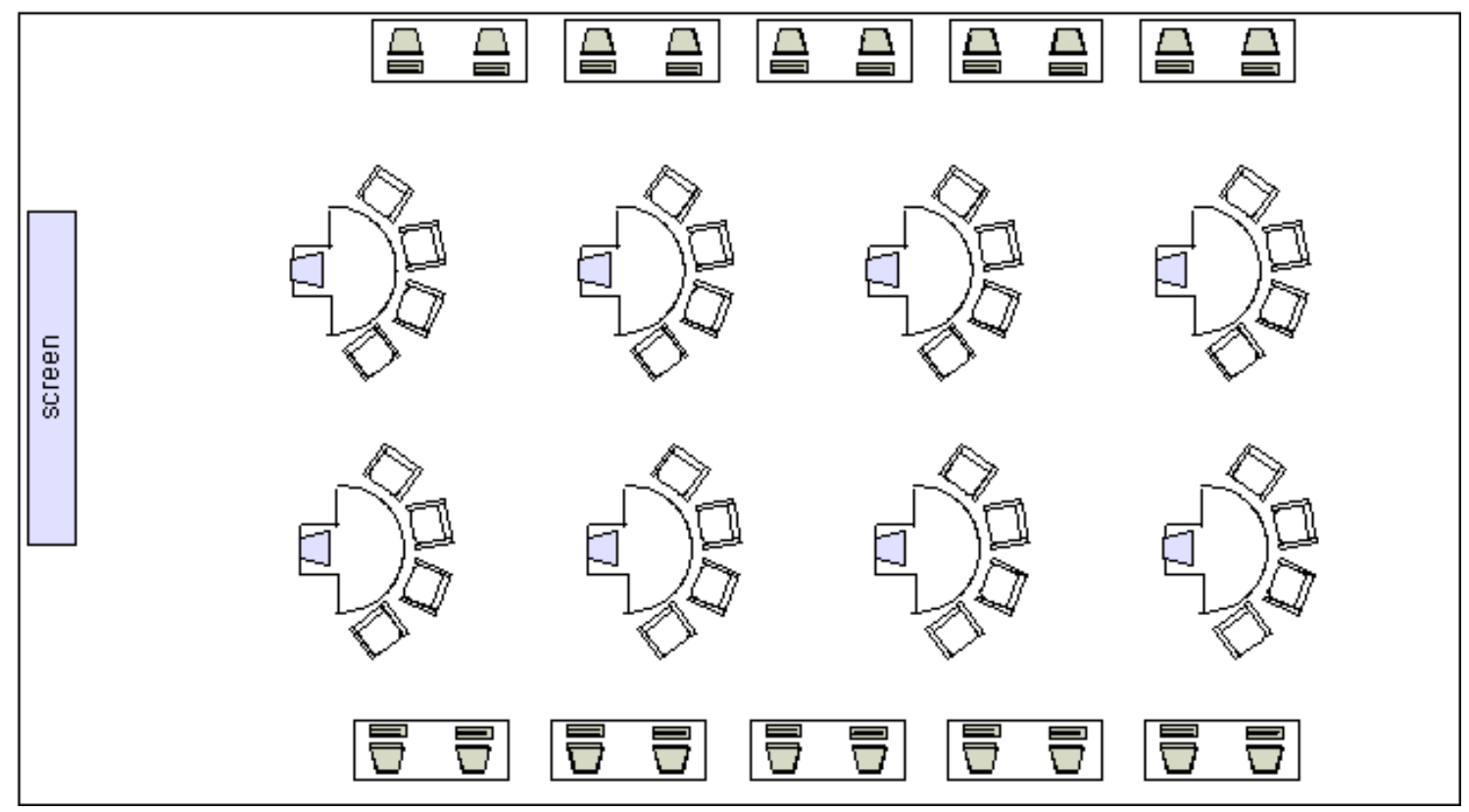

FIGURE 1: Classroom layout that seats up to 28 individual learners or 8 groups of up to $4-5$ people in the center stations. Students face the screen on the left during demonstrations. This room is designed to support group work, individual work, and instructor demonstrations.

Librarians have long recognized the value of tables that either accommodate or have been built specifically for group discussion and group study. However, while such tables can be found throughout most library facilities, they are rarely included in computer learning facilities. Tables designed for collaborative computer-learning allow several people to sit and interact comfortably and effectively. The most simple and inexpensive table designed for group work holds one computer with a monitor that is visible to all group members (Figure 2). Variant designs include the use of two or more low-profile monitors for better visibility among group members, or two or 
more keyboards for easy sharing of input activities. Another option is to have tables optimized for group work in which every member of the group has a dedicated computer (Figure 3). These are ideal for conducting both group and individual activities, but pose some challenges for lines of site and are more costly. For one-shot library instruction sessions, the single-computer-pergroup model may be most effective. For longer-term sessions, or for conducting exercises in which students work individually on activities that are later integrated as a whole group project, it may be advantageous to have tables at which each student has a dedicated computer.

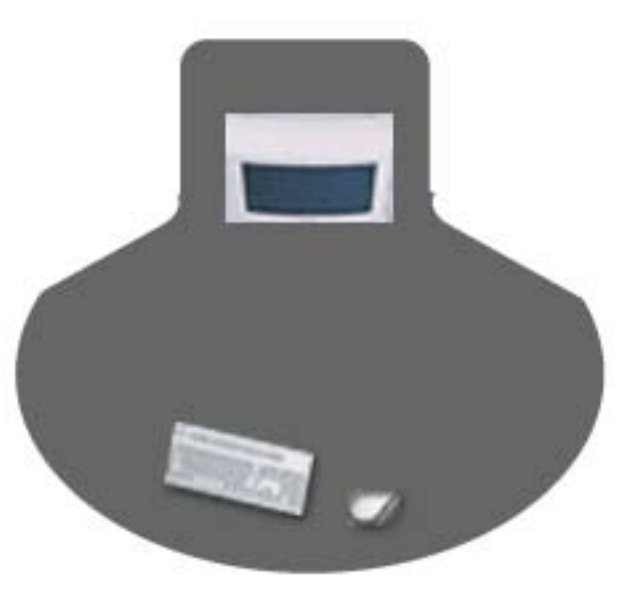

FIGURE 2: Table with one computer that is shared among several learners.

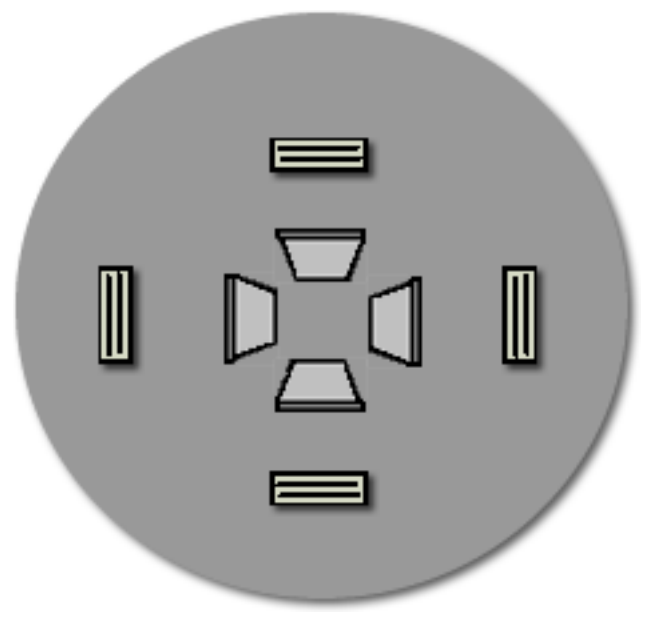

FIGURE 3: Table with several computers and low-profile monitors for group and individual work.

When selecting computer hardware for collaborative classrooms, unobtrusive designs are usually preferable. Low-profile monitors or those that can be partially recessed into modified tables can substantially improve line of sight. While notebook computers allow for flexible seating configurations, they generally provide poor visibility from side angles and, unless configured with a separate keyboard, sit too close to the keyboardist to provide good visibility to the rest of the group. The typical workstation for people with visual impairments will be of little 
benefit as a shared computer; instead, a separate ADA-compliant workstation integrated within a group-work table may be preferable.

When a collaborative-learning computer classroom is not available, almost any situation can be adapted, at least temporarily, for collaborative learning. Students are usually most willing to arrange themselves into makeshift group configurations for strategizing sessions and for group computing activities. During the first year that collaborative computer learning was used at Murphy Library, the library had no dedicated computer classroom of its own, and approximately fifteen group computer-learning sessions were conducted in traditional computer classrooms in various locations across campus. Students were instructed to form groups and to rearrange their seating configurations. One room, typical of those available, consisted of five rows of six computers each; in this room, students were usually arranged into five groups, one per row. Students were asked to put their jackets and backpacks along the periphery of the room so that they could more easily assemble around a single computer. Occasionally librarians encouraged students to rearrange their groups if some members had a blocked line of sight or when groups or individuals were marginalized due to awkward seating arrangements. The less-than-ideal facilities never hampered the effectiveness of the collaborative experience. In fact, some experiences were enhanced by the camaraderie of students and teachers as they rose above the physical limitations of their environment to embark on fulfilling learning experiences.

At Murphy Library, a room was eventually redesigned to accommodate both group and individual instruction methods. The floor plan is now configured so that eight computer workstations stand alone in the center of the room and an additional 20 computers are arranged along the periphery of the room, facing the side walls (see Figure 1). The eight stations in the center of the room are spaced so that four to five students can cluster around each workstation in 
comfort. With this arrangement, the room can accommodate 28 individual learners or up to 40 group learners. In group-learning situations, students move chairs away from wall-oriented workstations and place them around the tables in the center of the room. For individual computing, chairs are moved away from the center tables to the computers along the sides so that everyone has an individual workstation.

\section{STUDENT EXPECTATIONS}

When librarians at Murphy Library began using collaborative computer learning, they encountered a broad range of student expectations. While returning adult learners were more often willing and eager to participate, students in freshman English classes tended to react more hesitantly. They typically did not expect to encounter a collaborative learning situation, and some were reluctant to form groups and work with others. College students, although they desire challenging and meaningful learning environments, also rank a non-threatening environment as a priority (Dupuis 1999). Younger students, especially, are not always willing to take risks in peer situations, and the prospect of a social learning experience can compound any discomfort already felt at entering a new and unfamiliar classroom.

At Murphy Library, the problems associated with exposing students to this unexpected experience, although infrequent, usually occur at two intervals. The first is when students enter the room and discover that they are not going to be sitting and working alone. The second is after they have formed into groups and are asked for the first time to enter into discussions with fellow group members. These problems are usually temporary, and once students adjust, they participate willingly. 


\section{Initial Resistance}

Classroom experiences that get off to a positive, well-managed start are likely to continue to be successful. Librarians at Murphy Library used a variety of techniques to manage the entrance and seating of students and to establish a positive initial tone, including:

- Asking course instructors to prepare students prior to the day of the library session, perhaps even dividing the class into groups for the session;

- Greeting students at the door and directing them to group work tables;

- Announcing as students enter the room that groups will be formed, and repeating as more students enter;

- Displaying a large-font message on the projected instructor screen directing students to form groups at the group work tables;

- Taping a message on the monitors of individual-work (or extra) computers with a message similar to, “This computer not available. Please use one of the 8 computers in the center of the room. Form groups of 3-4 people per computer;”

- Using a random selection process or a previously determined method to form groups if the class seems unusually reluctant or if students have already become comfortable at individual computers.

In addition, librarians have found that students are more enthusiastic about collaborative learning when the pragmatic benefits are outlined. For example, students are likely to understand 
and welcome the practical advantages of group work when it is explained that members in their group may have special talents or experiences such as keyboard skills, computer skills, or library research experience.

\section{Subsequent Resistance}

The second point at which resistance may occur is when students are asked to begin their first group activity. This is usually not an issue for adult learners and upper-level classes, but younger students who are not used to working in groups or who are less secure in social settings may benefit from techniques designed to facilitate group conversations. A few techniques used by librarians at Murphy Library include:

- Explaining the rules and concepts of collaborative work before revealing the first exercise. This forces students to hold back their natural tendency to start the exercise and gives them the opportunity to concentrate on and comprehend the process;

- Promoting a lively and active environment by encouraging students to speak as freely and loudly as they wish in their group;

- Instructing groups to assign key responsibilities to members before they begin exercises. Examples include keyboarder, recorder, and speaker. This also helps break the conversational ice with a fairly safe, focused topic;

- Asking group members to introduce themselves to each other, even if they already know each other's names. They may be asked to add one personal fact to the introduction, such as where their home town is, or what their favorite sport is, etc. This activity helps reduce 
formality and sometimes forms a small, initial group bond, even if only to agree that the exercise seemed silly.

One librarian uses a space exploration metaphor to encourage participation, having groups imagine that they are on a quest to far-off "information galaxies." Students take on roles such as "pilot” (keyboarder), recorder of the "captain’s log” (note taker), "communications officer” (speaker for the group), and polite back-seat drivers.

Occasionally a group will gradually develop an unproductive dynamic resulting in poor internal communications. If a group seems to be too quiet, dominated by one individual, or otherwise dysfunctional, two options can result in significant change: either switch roles within the group; or announce a group personnel change, in which a member or two from each group must leave and join another group.

Students often enter library classrooms expecting to accomplish individual objectives such as finding materials for course assignments. In rooms that are configured to accommodate both group and individual computer instruction, this expectation can be met by dividing the class into two periods, one for collaborative work and the other for individual research. Or groups may work together on members' individual research needs, one person at a time. Regardless of how this expectation is managed, it is important to address students' need to do individual research, when this need exists. A thoughtful explanation of how the group experience will lead to greater efficiency in individual endeavors can be effective. 


\section{THE COLLABORATIVE TEACHING PERSONALITY}

Collaborative classrooms look and feel quite different from their traditional counterparts. They tend to be noisier and more spontaneous and may appear to be disorganized. Many librarians have been teaching for years in a culture where quietness and strict attention are equated with effective learning. Current learning theories, however, propose that students who are quietly and attentively focused on the teacher may not be learning as well as they could (Jensen, 2000). Given this rather substantial change in classroom dynamic, librarians may be concerned that their tried-and-true approaches to teaching may not be as effective in the collaborative computer classroom.

Collaborative classrooms do not require ostentatious, extroverted teaching techniques, nor do teachers need to be experts at improvisational strategizing. Librarians who are less comfortable managing conversations and activities extemporaneously can prepare a catalog of focus questions and activities in advance. They can allow the class to set its own direction within the framework of the curriculum and choose from their selection of questions and activities when appropriate. Other librarians may choose to provide only a structural framework and improvise the activities that take place therein. While some librarians will prefer a more conservative framework—-for example, a consistent pattern of demonstration, followed by group work, followed by discussion—others will wish to use more adventurous activities such as game playing. Just as with other methods of library instruction, the collaborative environment allows librarians to match their own comfort level in the teaching techniques they choose to use.

Collaborative teaching methods employ both proactive and reactive teaching techniques. While librarians need not change their teaching personalities to be effective in collaborative 
environments, some parts of the teaching process will be handled differently. On the one hand, librarians will be actively involved with students, communicating directly about objectives, expectations, and paths to achievement. Within the more spontaneous structure of the collaborative classroom, librarians may need to be more involved with this part of the process than in individualized-learning environments. On the other hand, librarians will spend a great deal of time "fading out," playing the role of a watchful facilitator whose direction may not always be necessary. This may feel quite different to librarians who are used to closely managing all classroom activities. Some librarians find themselves well suited to one role or the other, and it may take some time, practice, or professional development to feel comfortable in both roles. Collaborative computer learning also uses a very different and often unpredictable timeline than the more structured curricula of lecture-style teaching. The questions that arise from discussion following group activities often bring up topics planned for discussion later in the class period. Some librarians may feel comfortable changing their teaching plan, jumping forward and backward in their presentation slides or notes, while others may want to defer specific questions until later in the presentation.

Although collaborative classrooms may appear to be somewhat disorganized, behind the noise and apparent disorder are well-constructed plans that move individuals and groups toward specific objectives. The time-management techniques and curricular strategies described in the following sections allow librarians to divide classes into clearly-defined, easy-to-control segments with clear learning objectives. Librarians who use these techniques and strategies will find that regardless of their personality, teaching style, or individual approach, they can provide a sound framework that allows students the freedom of collaborative exploration while providing an unambiguous and manageable structure. 


\section{TIME MANAGEMENT}

Many library instruction sessions are still one-hour/one-shot classes (Hollister and Coe 2003). Even in this format, collaborative learning can be done effectively. Librarians must first plan how to schedule activities during the time allotted for the session. Some choices include:

- The class can alternate several times between librarian-led activities (such as demonstration or whole-class discussion) and collaborative work;

- A single period of time can be reserved for librarian-led activities followed by an extended collaborative work time;

- The entire class period can be collaborative work with occasional whole-class discussions;

- A single period of time can be reserved for collaborative learning activities followed by a period reserved for completing individual research.

Most of the sessions at Murphy Library consist of three activities: first lecture/demonstration, then group work time, then whole-class discussion. This is repeated as often as time allows. This structure of short, repeated activities provides many opportunities for the librarian to interact with groups, allows a customizable class schedule, brings up openings to fine tune groups and their activities, and helps keep the sessions lively and varied.

When discussing collaborative learning strategies, librarians often express concerns about trying to fit an already full agenda into a less structured environment. At first glance, it would 
appear that collaborative, student-led activities take more time than those led and controlled by the instructor. However, studies have shown that in computer classrooms where ground rules are well defined and the instructor is consistent with methods and techniques, collaborative learning is seen as time efficient and effective (Bevilacqua 2000). Librarians can maintain a schedule through use of specific, itemized agendas, in which activities are scheduled for specific lengths of time. While this might seem to exert a counterproductive control, well-designed curricula lead learners to anticipated, critical learning moments. These moments can be built into the agenda, which can then be rearranged on the fly to address questions and needs as they arise.

Librarians at Murphy Library use the following techniques to keep scheduled activities within specific time limits:

- Clearly state how long each activity will take. Measure in minutes;

- During group time, frequently announce how much time remains;

- If more than one activity is to be completed, make groups aware of where they may wish to be in relation to how much time remains;

- Apply time limits to post-activity processing as well as to lecture/demonstration periods;

- Have all time limits clearly posted on slides, whiteboards, handouts, etc.

Librarians found that although some activities did take more time than in individualized learning environments, they tended to spawn additional reinforcing activities that led to efficiencies in learning and retention of previous and subsequent activities. Librarians who taught the same class repeatedly were able to find a balance that allowed enough time to cover the same agendas as in individualized-learning sessions. In addition, librarians reported that the 
number of extraneous questions from individual participants and problems related to computer or navigation issues were substantially reduced, resulting in more efficient use of time.

Librarians also questioned whether collaborative learning was time-effective when teaching simple facts or process-oriented details. After experimentation, librarians at Murphy Library discovered that many details and specific instructions, which would normally be discussed as individual agenda items in non-collaborative settings, could be left unspoken in the collaborative classroom. These items were readily assimilated by learners while on the path to larger group goals, often through in-group dialog or through whole-class post-activity processing. For example, instead of spending class time lecturing and demonstrating the difference between a specific database’s “document types” and "publication types” limiters, groups completed larger-scale exercises in limiting, where they discovered first-hand the meaning of those and other limiters. Students who completed only a handful of group activities, each requiring substantial exploration of new territory, had been exposed to and required to use numerous specific resources features and process-oriented mechanisms. While students felt that

they may have experienced four or five topics, librarians felt that students had learned dozens of specific skills along the way.

\section{CURRICULAR STRATEGIES}

One librarian at Murphy Library remarked that it was a "liberating experience" to allow students to build their own understanding of the concepts and details he previously had tried to teach as a "sage on the stage.” Instead of leading 26 individuals to point and click their way into an information database, he simply told groups they had 2 minutes to find the database at the 
library's web site. Two minutes was usually far more than sufficient, and along the way students learned from their misplaced clicks, observed peripheral things together, and were responsible themselves for a very basic task that could seem condescending to be led through.

Simple, single-objective activities such as the two-minutes-to-a-database assignment are effective in collaborative environments, especially in short, one-shot sessions. Exercises need not be weighty or substantial to be successful. At Murphy Library, librarians purposefully build in quick, focused exercises among more in-depth activities to keep groups active and engaged. In one-hour/one-shot sessions, a rapid succession of short collaborative projects followed by focused whole-class discussions creates a crisp tempo that allows the class to cover a larger number of topics.

During hands-on group-work segments, the librarian circulates among groups, answering questions and providing guidance when needed. This is an excellent opportunity for the librarian to make note of questions coming from groups to share with the class as a whole after the activity. To keep groups focused on what is expected during each group-work activity, librarians sometimes display the objectives and the time allocation of the current activity on the instructor screen or distribute them in paper form. For activities that are complex or require in-depth investigation, examples or specific steps that facilitate the greater learning objective may be displayed or printed. However, for the collaborative experience to be most effective, instructions are not step-by-step, recipe-type directions.

Regardless of the length or nature of the group activity, the entire class benefits from whole-class discussions that take place after group activities. These post-activity exercises are known as "processing" in the field of experiential education, and are considered one of the essential elements of knowledge building among groups (Simpson 2003). In a typical form of 
processing used at Murphy Library, groups are asked to record and share with the whole class at least one comment or question as a result of each collaborative activity. For example, an activity in which students apply Boolean operators within a specific database might also include the assignment to identify the most successful search statement used within each group and to share it with the entire class during the discussion period. The combined group activity and subsequent whole-class discussion effectively leads learners through the process of discovery, practice, and reinforcement that seems necessary to fully understand concepts such as Boolean searching. Each group may also be asked to record and share one question that arises internally during a group exercise. An important factor in this assignment is that each group should agree upon a significant question even if it had found the answer along the way.

While the above examples of post-activity processing may seem basic and not new to library instruction, when implemented within a collaborative environment, they take on different characteristics and become more efficient and focused. The questions and comments that arise during processing are usually the result of internal group discussions, and they tend to be concentrated, focused, and relevant to all class members. The entire class moves forward through grass-roots experiences rather than instructor-contrived scenarios. In addition, when comments come from groups instead of individuals, one of the typical time-traps of the individual computer-learning classroom, in which entire classes may be held hostage by remedial or irrelevant questions from any number of the many participants, is effectively neutralized. Because each group is seen as a single participant, the management of extraneous input is limited to a few participants instead of to dozens.

Collaborative exercises that are designed to meet specific learning objectives and that allow learners to come to their own understanding of those objectives are most effective. Many 
individual hands-on exercises can be modified for collaborative learning. Keyser (2000, 36)

notes the importance of careful planning, suggesting that this "is not just any 'group work"” but that each exercise "should be chosen for the academic task and the students who must accomplish it.” In her article, Keyser (2000) also provides a number of examples of collaborative techniques for achieving specific leaning objectives. Several exercises in use at Murphy Library have also been included in the appendix of this article.

\section{CONCLUSION}

The experiences at Murphy Library reveal that collaborative learning can be integrated into computer classrooms in both ad-hoc and planned ways with effective results. The most successful experiences occur when librarians carefully address facility design, curricular strategies, student expectations, teaching styles, and classroom time management. While facilities designed to support collaborative learning clearly enhance the experience, classroom management and teaching strategies are of greater importance, and rewarding experiences can be created in almost any computer classroom. With a little practice, librarians can develop a store of techniques that facilitate group formation, interaction, and discussion, and that help create lively, active learning environments. Librarians can match their own teaching styles and personalities to the group-learning environment as they use techniques geared toward the facilitation of learning rather than the transmittal of information. Carefully planned agendas with firm time limits allow librarians to cover nearly the same amount of material as with individualized learning while respecting students' ability to solve both conceptual and process-oriented challenges. Librarians 
will find that most of the challenges that accompany the transition to collaborative learning are manageable and can be solved through the use of straightforward teaching strategies.

Librarians at Murphy Library who used the techniques described in this article found that most collaborative learning sessions were effective, positive experiences in which students learned well together and met classroom objectives. As other librarians implement collaborative learning within the computer classroom, developing their own approaches, they are likely to find themselves leading stimulating learning experiences in which students use their own initiative and capabilities to build solid understanding of the principles and specifics of information literacy. 


\section{APPENDIX: SAMPLE EXERCISES}

\section{Collaborative Learning Exercise: Find Subject Descriptor}

Objective: Understand the value of the thesaurus in the PsycINFO database;

\section{Steps:}

1. Groups are given 4 minutes to search for articles related to "body image."

2. Some groups are given printed instructions leading them to the thesaurus. Others are instructed to use free-text searching.

3. Groups are to record one question or comment about anything that happened during this exercise.

4. Whole class discussion takes place during which thesaurus searching is compared with free-text searching, and questions and comments are addressed.

Outcomes: students understand controlled vocabulary; students understand ways to discover subject descriptors; other related questions are answered.

\section{Collaborative Learning Exercise: Introduction to Library Web Site}

Objective: Become aware of the library home page and the category of "most popular" databases.

\section{Steps:}

1. Groups are given 3 minutes to find the library home page and the section that lists the "most popular" databases.

2. Groups are to record one question or comment about anything that happened during this exercise.

3. Groups share with the rest of the class their one question or comment.

Outcomes: students know how to find the library web site and this rather obvious category of resources, and have discussed peripheral items of interest.

\section{Collaborative Learning Exercise: Understand journal citations}

Objective: Understand the various elements of journal citations; get experience with library resources

\section{Steps:}

1. Groups are instructed to find the "Communication Studies" area of the library web site and select any database listed there.

2. Groups conduct a search on the topic of their choice and select one citation.

3. Groups record at least 4 critical parts of the citation that would be necessary to find the article elsewhere.

4. Groups record at least one question or comment about anything related to this activity.

5. Librarian displays a citation on the screen and points to parallels as groups share their results.

Outcomes: Students understand citations; they understand why they may need a citation; they understand terms such as "volume" and "issue;" other related questions are answered. 


\section{QUICK BIB:}

Bevilacqua, Mary. 2000. “Collaborative Learning in the Secondary English Class.” The Clearing House 73 (3): 132-133.

Keyser, Marcia W. 1999. “Active Learning and Cooperative Learning: Understanding the difference and using both styles effectively.” Research Strategies 17 (1 ): 35-44.

Will, Anne M. 1997. “Group learning in workshops.” New Directions for Adult \& Continuing Education (76), 33-41.

\section{REFERENCES}

Bevilacqua, Mary. 2000. “Collaborative Learning in the Secondary English Class.” The Clearing House 73 (3): 132-133.

Dabbour, Katherine Strober. 1997. “Applying Active Learning Methods to the Design of Library Instruction for a Freshman Seminar.” College \& Research Libraries 58 (4): 299-309.

Dupuis, Elizabeth A. 1999. “The Creative Evolution of Library Instruction.” Reference Services Review 27 (3): 287-291.

Drueke, Jeanetta. 1992. “Active Learning in the University Library Instruction Classroom.” Research Strategies 10 (2): 77-83.

Hollister, Christopher V. and Jonathan Coe. 2003. “Current Trends vs. Traditional Models: Librarians’ Views on the Methods of Library Instruction.” College \& Undergraduate Libraries 10 (2): 49-63.

Howe, Kenneth R. \& J. Berv. 2000. “Constructing Constructivism, Epistemological and Pedagogical.” In D.C. Phillips ed. Constructivism in Education: Opinions and second 
opinions on controversial issues. (Ninety-Ninth Yearbook of the National Society for the Study of Education). Chicago, IL. The National Society for the Study of Education.

Hung, David. W.L. 2002. "Metaphorical Ideas as Mediating Artifacts for the Social Construction of Knowledge: Implications from the Writings of Dewey and Vygotsky. International Journal of Instructional Media 29 (2): 197-215.

Huang, Hsin-jong and Shih-chung Lee. 2001. “Designing a Group Teaching Computer

Classroom.” [Chinese] Journal of Educational Media \& Library Sciences 39 (1): 70-84.

Jensen, Eric. 2000. Brain-based Learning. San Diego, CA: The Brain Store.

Keyser, Marcia W. 1999. “Active Learning and Cooperative Learning: Understanding the difference and using both styles effectively.” Research Strategies 17 (1 ): 35-44.

Lowery, Lawrence. 1998. “Strategies for Instruction.” Foss 11 (Spring): 6-9.

McLoughlin, Catherine, and Ron Oliver. 1998. "Maximising the Language and Learning Link in Computer Learning Environments.” British Journal of Educational Technology 29 (2): 125-36.

Simpson, Steven V. 2003. The Leader Who is Hardly Known: Self-less Teaching from the Chinese Tradition. Oklahoma City, OK: Wood and Barnes Press.

Will, Anne M. 1997. “Group Learning in Workshops.” New Directions for Adult \& Continuing Education 76 (Winter): 33-41.

Yiping, Lou, Philip C. Abrami, and Sylvia d'Apollonia, S. 2001. "Small Group and Individual Learning with Technology: A Meta-Analysis.” Review of Educational Research 71 (3): 449-522. 